www.jmscr.igmpublication.org

Impact Factor 5.84

Index Copernicus Value: 83.27

ISSN (e)-2347-176x ISSN (p) 2455-0450

crossref DOI: https://dx.doi.org/10.18535/jmscr/v5i1.134

Journal Of Medical Science And Clinical Research

\title{
Post Traumatic Disability among Patients with Head Injury in a Tertiary Care Centre
}

\author{
Authors \\ Sharmad M S ${ }^{1}$, Raj S Chandran ${ }^{2}$, Sabina S R ${ }^{3}$, Rajmohan $K^{4}$, Anilkumar $\mathbf{P}^{5}$ \\ ${ }^{1}$ Additional Professor, Department of Neurosurgery, Medical College, Trivandrum \\ ${ }^{2}$ Associate Professor, Department of Neurosurgery, Medical College, Trivandrum \\ ${ }^{3}$ MSc Nursing, Medical College, Trivandrum \\ ${ }^{45}$ Professor and HOD, Dept of Paediatrics, Medical College, Karakkonam \\ ${ }^{5}$ Professor and HOD, Department of Neurosurgery, Medical College, Trivandrum
}

\begin{abstract}
Background: Traumatic Brain injury, according to the World Health Organization, will surpass many diseases as a major health problem and leading cause of disability by the year 2020.It can have far reaching consequences and will affect the physical, psychological and socioeconomic status of not only the individual but his family and the entire society in the long run.

Aim: The objective of the study was to estimate the proportion of the post traumatic disability among patients with head trauma and to determine the association of selected variables with post traumatic disability.

Materials and Methods: A cross sectional study was conducted on a sample of 200 head injury patients. Results: The study showed that $62 \%$ of patients with head trauma had functional impairment and $47 \%$ had cognitive impairment. The study findings show that a statistically significant association exit between the variables age, place of residence, financial status, cause of injury, history of alcoholism, duration of hospitalization with post traumatic disability in terms of functional impairment. Statistically significant association was also observed between occurrence of seizure episodes and cognitive impairment of patients after head trauma.

Conclusion: Early detection and intervention of disability in patients with traumatic brain injury can go a long way towards reducing the burden of disability in the society.

Keywords: post traumatic disability; functional impairment; cognitive impairment.
\end{abstract}

\section{Introduction}

Traumatic brain injury is the leading cause of death and disability in children and young adults around the world and is involved in nearly half of all trauma deaths. Many years of productive life are lost, and many people have to suffer years of disability after brain injury. In addition, it engenders great economic costs for individuals, families and society. Traumatic brain injury is a major public health problem, especially among male adolescents and young adults ages 15 to 24 , and among elderly people 75 years and older. With an estimated 10 million people affected annually worldwide by TBI, the burden of mortality and morbidity of TBI makes it a major public health problem. 
Estimates from the United States indicate that 1$2 \%$ of the population, i.e. around five million people, live with a TBI disability. At the national level, nearly two million people sustain brain injuries, 0.2 million lose their lives and nearly a million need rehabilitation services every year. The demographic, epidemiological and economic transition in India has changed the health scenario in a significant way during the last two decades. This shift in health problems and priorities has brought the entire spectrum of non communicable diseases and injuries to the forefront of health care delivery system. Road traffic injuries are the leading cause $(60 \%)$ of brain injury, followed by falls $(20-25 \%)$ and violence (10\%). Meagre prehospital care with added delay in emergency care has only added further to rising mortality and disability rates.

Treatment is multidisciplinary and includes pharmacotherapy, physical therapy, occupational therapy, recreation therapy, speech therapy, and vocational rehabilitation. Cognitive rehabilitation is also important, especially during the first 6 months after injury, and involves techniques to retrain the patient in specific domains by providing a series of mental stimuli, tests, and activities. Tertiary prevention with comprehensive physical, psychological and vocational rehabilitation measures can reduce disabilities due to TBI and consequently improve quality of life.

\section{Objectives of the Study}

Primary objective: Estimate the proportion of the post traumatic disability among patients with head trauma admitted in Medical College Hospital Thiruvananthapuram. In this study, post traumatic disability refers to impairment in terms of functional and cognitive, as assessed by socio demographic and clinical performa, Barthel Index and Hindi Mental Status Examination (HMSE).

Secondary objective: Determine the association of selected variables with post traumatic disability.

\section{Materials and Methods}

In this study, the research approach is quantitative. The present study was a cross sectional study to assess the proportion of post traumatic disability among head trauma patients and its associated factors. The study was conducted in the Department of Neurosurgery, Medical College Hospital, Thiruvananthapuram. In this study, 200 patients with head trauma on follow up treatment satisfying the inclusion and exclusion criteria were selected consecutively from neurosurgery outpatient department and head injury clinic in Medical College Hospital, Thiruvananthapuram, during the period of study.

\section{Inclusion criteria}

- Patients aged $>13$ years with GCS $\leq 13$ on admission.

- Patients, who had completed 6 weeks following head trauma.

- Patients and care givers, who are willing to participate.

\section{Exclusion criteria}

- Patients admitted in Medical College with polytrauma or spinal cord injury• Patients $>70$ years and has age related cognitive / mobility problems.

- Patients with associated neurological /psychiatric problems.

Informed consent was taken from the patients, who were willing to participate in the study. The data were collected by using structured interview schedule and by observation. The clinical data were confirmed by the review of medical records. Socio Demographic Data include age, gender, education, occupation, habits, type of injury, monthly income, and area of residence. Clinical Profile includes time and onset of injury, cause, type of injury, co-morbidities, GCS score, CT findings, diagnosis and surgery done.Functional impairment was measured using Barthel Index and cognitive impairment using HMSE score. 


\section{Statistical Analysis}

The data obtained from the subjects were grouped and analyzed using appropriate statistical tests. Descriptive and inferential statistics were used for analysis of data. Data were entered using Microsoft Excel 2007 worksheet and analyzed using SPSS software. All the variables were described in terms of frequency, percentage, mean and standard deviation where ever appropriate. The proportion of post traumatic disability in patients with head trauma were estimated in terms of functional impairment using Barthel Index and cognitive impairment in terms of HMSE score with 95\% Confidence Interval. Determination of association between post traumatic disability (functional and cognitive impairment) and sociodemographic and clinical variables was done.

\section{Results}

$11.5 \%$ of patients were in the age group of $13-20$ years, $24.5 \%$ were in the age group of $21-30$ years, $14.5 \%$ were in the group $31-40$ years, $20.0 \%$ were in the age group $41-50$ years, $16.0 \%$ were in the age group 51 - 60 years and remaining in $61-70$ years. Average age of the patients was $40.3 \pm 15.8$ years and age ranged from 13 to 70 . The Median age 40 years with inter quartile ranged 26 to 52 years. $74.5 \%$ of the patients were males and $25.5 \%$ were females.52.5\% of the patients were from urban and $47.5 \%$ were from rural.44.5\% of the patients had studied up to high school level. $82.0 \%$ were below poverty line category.

$36.0 \%$ of the patients consumed alcohol, $9.5 \%$ had both smoking and alcohol consumption .75.5\% patients had no co morbidities, $11.0 \%$ had hypertension, $6.5 \%$ had diabetes, and $7.0 \%$ had heart disease.7.5\% of patients had history of fall, $89.0 \%$ had RTA, $1.0 \%$ had sports injury and $2.5 \%$ had assault. Out of $92.0 \%$ patients suffered from RTA, $82.5 \%$ travelled on two wheeler,5.5\% on three wheeler, $2.5 \%$ on four wheeler, $1.5 \%$ were pedestrian. Pre disposing factors for RTA was over speed $(35.5 \%)$ and in $48.5 \%$ other causes, which included bad weather, poor condition of the road, not following traffic rules etc.

$15.5 \%$ had ventilator support, $35.0 \%$ had undergone surgical intervention and7.5\% had seizure episode during hospitalization.68.0\% had $\mathrm{SDH} / \mathrm{EDH}$ in their CT report,5.5\% had ICH, $6.5 \%$ had fracture skull.62.0\% of patients were hospitalized for $1-2 \mathrm{wks}, 20.0 \%$ had $\leq 1$ week of hospitalization. $58.0 \%$ of patients suffered from mild injury, 24.0\% had severe injury.

Based on scores obtained in Barthel Index, 5.5\% had total dependence, $12.5 \%$ had severe dependence, $44.0 \%$ had moderate dependence, $32.0 \%$ had slight dependence, $6.0 \%$ were performing their daily functions. Based on scores obtained in HMSE, 53.0\% had normal cognition, $41.0 \%$ had mildcognitive impairment, $4.5 \%$ had moderate cognitive impairment and $1.5 \%$ had severe cognitive impairment. The proportion of patients with post traumatic disability in terms of functional impairment as measured by Barthel Index $(\leq 91)$ were $62.0 \%$ with $95 \%$ CI $(55.1 \%$ $68.4 \%)$. The proportion of patients with post traumatic disability in terms of cognitive impairment as measured by HMSE $(\leq 27)$ were $47.0 \%$ with $95 \%$ CI (40.2\% - 53.9\%).

Association of post traumatic disability in terms of functional impairment with sociodemographic variables like age, gender, place of residence, financial status, education, occupation, habits and comorbidities were assessed. $p$ value of $<0.05$ was taken as significant. The variables age, place of residence, financial status and educational status had statistically significant association with post traumatic disability.

Age of patients with TBI and Post traumatic disability (functional) had a statistically significant association. Patients, who belonged to age group 40 years and above (69.7\%) were found to have more functional impairment (moderate to severe dependence) than those, who were less than 40years of age (54.5\%). Significant association was observed between area of residence and functional post traumatic disability. Patients, who lived in rural (71.6\%) were found to 
have a higher percentage of functional impairment (moderate to severe dependence) than those, who were from urban (53.3\%). A significant association $(\mathrm{p}=0.008)$ was observed between financial status and functional disability. Patients, who belonged to BPL status $(81.1 \%)$, had higher proportion of functional impairment (moderate to severe dependence) than patients, who belonged to APL $(57.7 \%)$.

The variables like cause of injury, skull injury, history of alcoholism at the time of injury, surgical intervention, seizure episodes during hospitalization had statistically significant association with functional post traumatic disability. Patients, who had other causes of injury (86.4\%) were found to have moderate to severe dependence than those, who suffered from RTA (59.0\%).Patients, who had skull injury $(96.2 \%)$ were found to have moderate to severe dependence than those who had no skull fracture
(96.2\%). Patients, who had history of alcoholism $(95.5 \%)$ were found to have moderate to severe dependence than those, who had no history of alcoholism (57.9\%). Patients, who had not undergone surgical intervention (71.4\%), were found to have higher functional impairment (moderate to severe dependence)than those, who had undergone surgical intervention (56.9\%).

Patients with seizure (86.7\%) were found to have an increase in moderate to severe dependence than those, who had no seizure episodes $(60.0 \%)$.

Significant association was not found between post traumatic disability interms of cognitive impairment and Socio demographic variables of the patients. Significant association was seen between occurence of seizure episodes during hospitalisation and cognitive impairment. Patients with seizure were found to have an increase in moderate to severe cognitive impairment $(73.3 \%)$ than those, who had no seizure episodes(44.9\%).

Table 1 Distribution of patients based on scores obtained in Barthel Index Functional Impairment

\begin{tabular}{lll}
\hline Functional Impairment & Frequency & Percent \\
\hline Total dependence & 11 & 5.5 \\
Severe dependence & 25 & 12.5 \\
Moderate dependence & 88 & 44.0 \\
Slight dependence & 64 & 32.0 \\
Independence & 12 & 6.0 \\
Total & 200 & 100.0 \\
\hline
\end{tabular}

Table 2 Estimation of proportion of post traumatic disability (functional and cognitive impairment)

\begin{tabular}{lcc}
\hline Post traumatic disability & Percentage of proportion & $95 \%$ CI \\
\hline Functional impairment & & \\
Cognitive impairment & $62.0 \%$ & $55.1 \%-68.4 \%$ \\
& $47.0 \%$ & $40.2 \%-53.9 \%$ \\
\hline
\end{tabular}


Table 3 Association of post traumatic disability in terms of functional impairment with Socio demographic variables.

$$
\mathrm{N}=200
$$

Functional Impairment

\begin{tabular}{|c|c|c|c|c|c|c|c|c|}
\hline \multicolumn{2}{|c|}{ Variables } & \multirow{2}{*}{$\begin{array}{c}\text { Present } \\
\text { N }\end{array}$} & \multicolumn{2}{|c|}{ Absent } & \multicolumn{2}{|c|}{ Total } & \multirow{2}{*}{$\begin{array}{l}\mathrm{X}^{2} \\
\%\end{array}$} & \multirow[t]{2}{*}{$\mathrm{P}$} \\
\hline & & & $\%$ & $\mathrm{~N}$ & $\%$ & $\mathrm{~N}$ & & \\
\hline \multirow[t]{3}{*}{ Age } & $\geq 40$ & 69 & 69.7 & 30 & 30.3 & 99 & 100 & \\
\hline & & & & & & & & 4.9300 .026 \\
\hline & $<40$ & 55 & 54.5 & 46 & 45.5 & 101 & 100 & \\
\hline \multirow[t]{3}{*}{ Gende } & Male & 88 & 59.1 & 61 & 40.9 & 149 & 100 & \\
\hline & & & & & & & & 2.1430 .143 \\
\hline & Female & 36 & 70.6 & 15 & 29.4 & 51 & 100 & \\
\hline \multirow{3}{*}{$\begin{array}{r}\text { Place o } \\
\text { Residen }\end{array}$} & Rural & 68 & 71.6 & 27 & 28.4 & 95 & 100 & \\
\hline & & & & & & & & 7.0470 .008 \\
\hline & Urban & 56 & 53.3 & 49 & 46.7 & 105 & 100 & \\
\hline \multirow{4}{*}{$\begin{array}{r}\text { Financi } \\
\text { Status }\end{array}$} & APL & 30 & 57.7 & 7 & 18.9 & 37 & 100 & \\
\hline & & & & & & & & 7.0160 .008 \\
\hline & $\mathrm{BPL}$ & 94 & 81.1 & 69 & 42.3 & 163 & 100 & \\
\hline & $\begin{array}{l}\text { Primary or } \\
\text { below }\end{array}$ & 43 & 72.9 & 16 & 27.1 & 59 & 100 & \\
\hline \multirow[t]{2}{*}{ Educati } & & & & & & & & 4.2060 .04 \\
\hline & High school & 81 & 57.4 & 60 & 42.6 & 141 & 100 & \\
\hline \multicolumn{2}{|c|}{ Unemployed/Unskilled workers } & 77 & 58.8 & 54 & 41.2 & 131 & 100 & \\
\hline \multicolumn{2}{|c|}{ Occupation } & & & & & & & 1.6720 .196 \\
\hline \multicolumn{2}{|c|}{ Skilled workers } & 47 & 68.1 & 22 & 31.9 & 69 & 100 & \\
\hline \multirow[t]{3}{*}{ Habits } & Bad habits & 73 & 62.4 & 44 & 37.6 & 117 & 100 & \multirow{3}{*}{0.0180 .892} \\
\hline & & & & & & & & \\
\hline & No bad habits & 51 & 61.4 & 32 & 38.6 & 83 & 100 & \\
\hline & Comorbidities & 35 & 71.4 & 14 & 28.6 & 49 & 100 & \multirow{3}{*}{2.4490 .118} \\
\hline \multicolumn{2}{|c|}{ Comorbidities } & & & & & & & \\
\hline & No comorbidities & 89 & 58.9 & 62 & 41.1 & 151 & 100 & \\
\hline
\end{tabular}


Table 4 Univariate analysis to determine the association of post traumatic disability in terms of functional impairment with clinical variables

$$
\mathrm{N}=200
$$

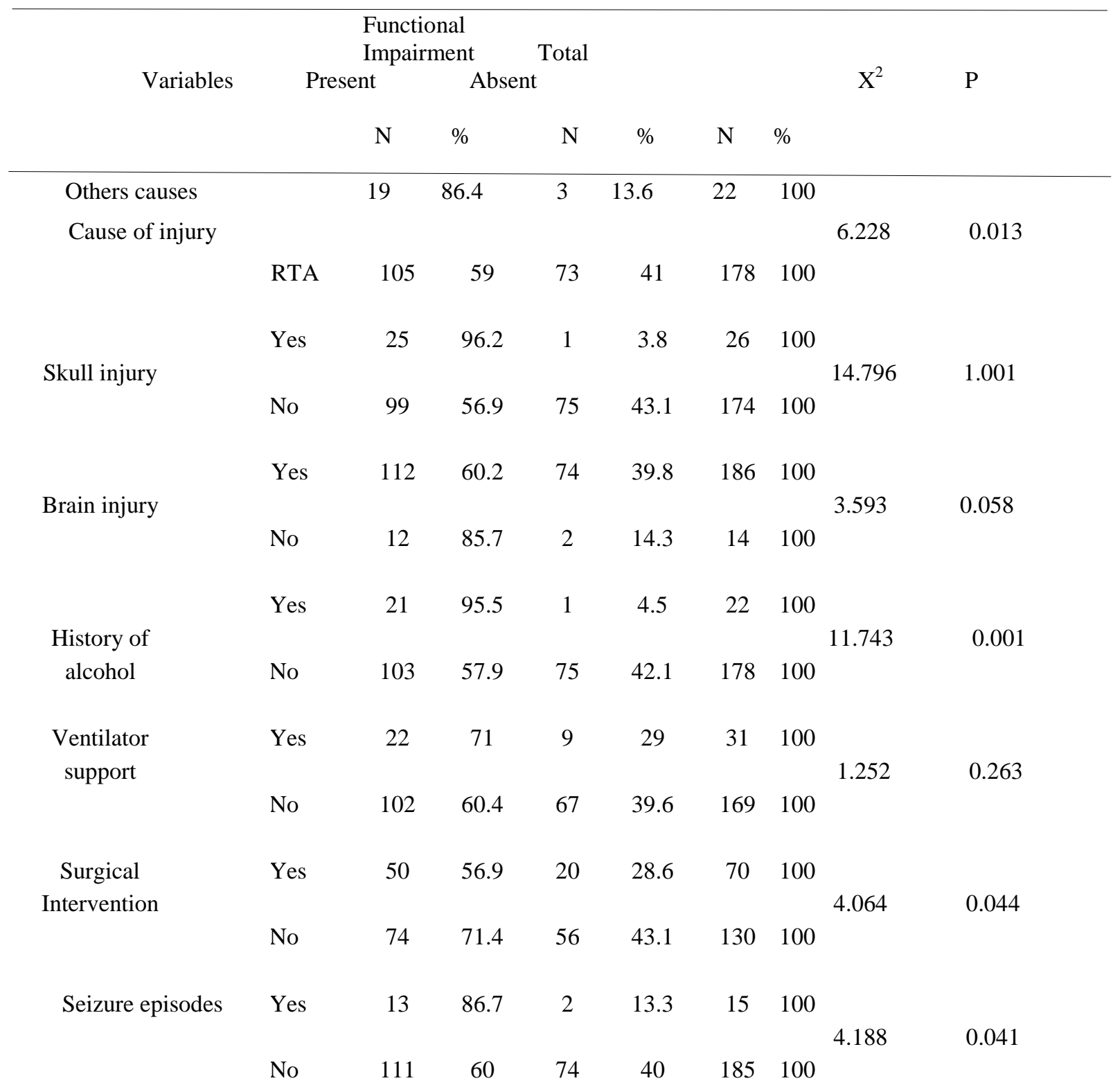


Tables 5 Association of post traumatic disability in terms of cognitive impairment with Socio demographic variables.

\begin{tabular}{|c|c|c|c|c|c|c|c|c|c|}
\hline \multirow[t]{2}{*}{ Variables } & & \multicolumn{2}{|c|}{$\begin{array}{l}\text { Cognitive } \\
\text { Impairment } \\
\text { Present }\end{array}$} & \multicolumn{2}{|c|}{$\begin{array}{c}\text { Total } \\
\text { Absent }\end{array}$} & \multirow[b]{2}{*}{$\mathrm{N}$} & \multirow[b]{2}{*}{$\%$} & \multirow[t]{2}{*}{$\mathrm{X}^{2}$} & \multirow[t]{2}{*}{$\mathrm{P}$} \\
\hline & & $\mathrm{N}$ & $\%$ & $\mathrm{~N}$ & $\%$ & & & & \\
\hline \multirow[t]{3}{*}{ Age } & $<40$ & 48 & 47.5 & 53 & 52.5 & 101 & 100 & & \\
\hline & & & & & & & & 0.023 & 0.881 \\
\hline & $\geq 40$ & 46 & 46.5 & 53 & 53.5 & 99 & 100 & & \\
\hline \multirow[t]{3}{*}{ Gender } & Male & 71 & 74.7 & 78 & 52.3 & 149 & 100 & & \\
\hline & & & & & & & & 0.099 & 0.753 \\
\hline & Female & 23 & 45.1 & 28 & 54.9 & 51 & 100 & & \\
\hline Place of & Rural & 49 & 51.6 & 46 & 48.4 & 95 & 100 & & \\
\hline Residence & Urban & 45 & 42.9 & 60 & 57.1 & 105 & 100 & & \\
\hline \multirow{3}{*}{$\begin{array}{c}\text { Financial } \\
\text { Status }\end{array}$} & APL & 15 & 405 & 22 & 59.5 & 37 & 100 & & \\
\hline & & & & & & & & 0.760 & 0.383 \\
\hline & BPL & 79 & 48.5 & 84 & 51.5 & 163 & 100 & & \\
\hline \multirow{4}{*}{$\begin{array}{c}\text { Duration } \\
\text { Illness }\end{array}$} & $>6$ weeks & 30 & 50 & 30 & 50 & 60 & 100 & & \\
\hline & & & & & & & & 0.310 & 0.578 \\
\hline & $\leq 6$ weeks & 64 & 45.7 & 76 & 54.3 & 140 & 100 & & \\
\hline & $\begin{array}{l}\text { Primary or } \\
\text { below }\end{array}$ & 26 & 44.1 & 33 & 55.9 & 59 & 100 & & \\
\hline \multirow[t]{3}{*}{ Education } & & & & & & & & 0.289 & 0.591 \\
\hline & High school & 68 & 48.2 & 73 & 51.8 & 141 & 100 & & \\
\hline & Unemployed/ & 63 & 48.1 & 68 & 51.9 & 131 & 100 & & \\
\hline \multirow[t]{2}{*}{ Occupation } & $\begin{array}{l}\text { Unskilled } \\
\text { workers }\end{array}$ & & & & & & & 0.182 & 0.67 \\
\hline & Skilled workers & 31 & 44.9 & 38 & 55.1 & 69 & 100 & & \\
\hline \multirow[t]{3}{*}{ Habits } & Bad habits & 52 & 44.4 & 65 & 55.6 & 117 & 100 & & \\
\hline & & & & & & & & 0.739 & 0.39 \\
\hline & No bad habits & 42 & 50.6 & 41 & 49.4 & 83 & 100 & & \\
\hline \multirow{3}{*}{ Comorbidities } & Comorbidities & 23 & 46.9 & 26 & 53.1 & 49 & 100 & & \\
\hline & & & & & & & & 0.000 & 0.992 \\
\hline & No comorbidities & 71 & 47 & 80 & 53 & 151 & 100 & & \\
\hline
\end{tabular}


Table 6 Association of post traumatic disability in terms of cognitive impairment with clinical varialbes. $\mathrm{N}=200$

\begin{tabular}{|c|c|c|c|c|c|c|c|c|c|}
\hline \multirow{3}{*}{ Variables } & \multicolumn{7}{|c|}{ Functional Impairment } & \multirow[b]{3}{*}{$X^{2}$} & \multirow[b]{3}{*}{$\mathrm{P}$} \\
\hline & & \multirow{2}{*}{\multicolumn{2}{|c|}{ Present }} & & & & & & \\
\hline & & & & \multicolumn{2}{|c|}{ Absent } & & & & \\
\hline \multirow{3}{*}{ RTA } & Others & 13 & 59.1 & 9 & 40.9 & 22 & 100 & \multirow{3}{*}{1.451} & \multirow{3}{*}{0.228} \\
\hline & & & & & & & & & \\
\hline & RTA & 81 & 45.5 & 97 & 54.5 & 178 & 100 & & \\
\hline \multirow{3}{*}{ Skull } & Yes & 16 & 61.5 & 10 & 38.5 & 26 & 100 & \multirow{3}{*}{2.536} & \multirow{3}{*}{0.111} \\
\hline & & & & & & & & & \\
\hline & No & 78 & 44.8 & 96 & 55.2 & 174 & 100 & & \\
\hline \multirow{3}{*}{ Brain } & Yes & 87 & 46.8 & 99 & 53.2 & 186 & 100 & \multirow{3}{*}{0.054} & \multirow{3}{*}{0.816} \\
\hline & & & & & & & & & \\
\hline & No & 7 & 50 & 7 & 50 & 14 & 100 & & \\
\hline \multirow{3}{*}{$\begin{array}{c}\text { History of } \\
\text { alcohol }\end{array}$} & Yes & 13 & 59.1 & 9 & 40.9 & 22 & 100 & \multirow{3}{*}{1.451} & \multirow{3}{*}{0.228} \\
\hline & & & & & & & & & \\
\hline & No & 81 & 45.5 & 97 & 54.5 & 178 & 100 & & \\
\hline \multirow{2}{*}{$\begin{array}{c}\text { Ventilator } \\
\text { support }\end{array}$} & Yes & 17 & 54.8 & 14 & 45.2 & 31 & 100 & \multirow{2}{*}{0.905} & \multirow{2}{*}{0.341} \\
\hline & No & 77 & 45.6 & 92 & 54.4 & 169 & 100 & & \\
\hline \multirow[t]{3}{*}{ Surgery } & Yes & 38 & 54.3 & 32 & 45.7 & 10 & 100 & \multirow{3}{*}{2.295} & \multirow{3}{*}{0.13} \\
\hline & & & & & & & & & \\
\hline & No & 56 & 43.1 & 74 & 56.9 & 130 & 100 & & \\
\hline \multirow[t]{3}{*}{ Seizure episodes } & Yes & 11 & 73.3 & 4 & 26.7 & 15 & 100 & \multirow{3}{*}{4.514} & \multirow{3}{*}{0.034} \\
\hline & & & & & & & & & \\
\hline & No & 83 & 44.9 & 102 & 55.1 & 185 & 100 & & \\
\hline
\end{tabular}

\section{Discussion}

In the present study, median age of traumatic brain injury was 40 years with inter quartile range 26 to 52 years. This was close to study conducted in NIMAHS where the median age was 30.6 to 47.6 years ${ }^{1}$.A retrospective, population-based study of 62 survivors of working-age with moderate-to severe TBI injured in 1995/1996, and hospitalized at the Trauma Referral

Center in Eastern Norway found that the mean current-age was 40.8 years ${ }^{2}$. Another study from India showed that in patients with TBI, age demonstrates independent association with unfavorable outcome at 6 months, in stepwise manner centered on a threshold of 40 years.

In this study, $74.5 \%$ of the patients were males and $25.5 \%$ were females. An 8 year study of 56 hospitals in Taiwan also showed similar patterns of injuryamong the pediatric TBI group with a male to female ratio of $1.6: 1^{3}$. In the present study majority of patients had road traffic accident as the main cause of head trauma .This was supported by a study, which indicate that the majority of TBI cases $(60.0 \%)$ are as a result of 
RTA, followed by falls (20.0-30.0\%), and violence $(10.0 \%){ }^{4}$.Overall, motor vehicle or related transportation accidents and falls comprisethe most common cause of TBI. Transportation accidents, particularly for young males (15 to 24 years), by some estimates account for more than $50 \%$ of all head injuries ${ }^{5}$.In the present study $68.0 \%$ had SDH/ EDH in their CT report, 20.0\% had Concussion/ Contusion, 5.5\% had ICH, 6.5\% had Fracture skull. A study done in Bangalore revealed that concussion, contusion, and skull fractures constituted $35.5 \%, 32.3 \%$ and $11.7 \%$, respectively and $13.0 \%$ were diagnosed to have brain hemorrhages ${ }^{1}$.

In the present study the proportion of patients with post traumatic disability in terms of functional impairment as measured by Barthel Index $(\leq 91)$ were $62.0 \%$ with $95 \%$ CI ( $55.1 \%-68.4 \%)$ and the proportion of patients with post traumatic disability in terms of cognitive impairment as measured by HMSE $(\leq 27)$ were $47.0 \%$ with $95 \%$ CI (40.2\%-53.9\%). A community based study showed that the estimated prevalence of disability (with severe difficulty) was $3.6 \%$ and $13.4 \%$ for disability with moderate difficulties. Another study conducted on prevalence of Long-Term Disability From TraumaticBrain Injury in the Civilian Population of the United States reveals that an estimated $1.1 \%$ of the US civilian population or 3.17 million people (95\% CI: $3.02-$ 3.32million) were living with a long-term disability from TBI. An estimated $43.3 \%$ ofAmericans have residual disability 1 year after injury. The most recent estimate of theprevalence of US civilian residents living with disability following hospitalizationwith TBI is 3.2 million ${ }^{6}$.Study conducted in NIMHANS, Bangalore regarding disability and quality oflife showed that during the one-year follow-up period, nearly $(67.0 \%)$ patients werestill continuing treatment in different centers for various health problems anddisabilities ${ }^{1}$.

In the present study, significant association between functional and cognitive impairment was also found out .It showed a significant association between age, place of residence, financial status, cause of injury, history of alcoholism, duration of hospitalization with post traumatic disability in terms of functional impairment. Occurrence of seizure episodes and cognitive impairment had significant association. In a cohort study of S SD and apani et al. (2010) the authors concluded that older age at the time of injury was associated with poorer performance on various cognitive domains. There was significant association of unfavorable outcome with age $>40$ years in all the subgroups ${ }^{7}$. Another study showed that longer length of stay in hospital is often necessary to address their slower rates of functional gain. A follow-up study conducted by Dombovy \& Olek at three and six months, residual physical disability, as measured by the Functional Independence Measure, was minimal. At six months, the unemployment rate of participants studied was $60.5 \%{ }^{8}$.

Study conducted on disability associated with exposure to traumatic events, hierarchical regression analysis showed that, for both men and women, exposure to traumatic events, older age and living in a polygamous marriage increased the likelihood of having a disability. A prospective study results showed that gender, minority status, age, substance abuse, and residence in a zip code with low average income were associated with intentional TBI. Multivariate analysis found minority status and substance abuse to be predictive of intentional injury after adjusting for other demographic variables studied. Intentional TBI was predictive of mortality and anatomic severity of injury to the head. Penetrating intentional TBI was predictive of injury severity with all injury severity markers studied ${ }^{9}$.

In the present study, significant association was seen between skull injury and post traumatic disability (functional). Patients, who had skull injury $(96.2 \%)$ were found to have an increase in moderate to severe dependence than who had no skull fracture (96.2\%). In addition to the level of unconsciousness at admission, age, pupillary light reactions, intracranial hematoma, associated extra 
cranial injuries, and skull fractures seem to be important for predicting the outcome ${ }^{10}$.

\section{Conclusion}

Awareness about the disability after head injury can promote early detection and management of disability. Health education and counseling for patients and relatives is an important measure to improve the quality of life the patients. Rehabilitation measures may include speech and language therapy, cognitive rehabilitation, andpsychological, physical, and occupational therapy, some of which may started while the patient is in the ICU.

The study findings can be used for preparing care guide which can be used forrehabilitation patients sustained with head trauma. We can plan various health programmes to the patients in preventive, promotive and rehabilitative domains of post traumatic disability among head trauma patients. We can set up separate clinics associated with outpatient Department to provide heath education and a care guide regarding post traumarehabilitation for patients who come up for the follow up visits. Community level rehabilitation programmes and self help groups may beorganized for patients having disability after sustaining head injury

\section{Limitations}

This study has included only patients attending department of Neurosurgery.

\section{References}

1. G Gururaj, Kolluri S.V.R., Chandramouli B.A, Subbakrishna D.K \& Kraus JF. Traumatic Brain Injury; National Institute of Mental Health \&Neuro Sciences, Publication. 2005; 61: 1-53

2. Suzanne Polinder, Juanita A Haagsma, David van Klaveren, Ewout W Steyerberg, Ed F van Beeck, Health-related quality of life after TBI: a systematic review of study design, instruments, measurement properties, and outcome, Population Health Metrics. 2015; 13(1).

3. Dr. Remadevi C Trauma epidemiology and duration of hospitalization Kerala calling April 2005; 34-35.

4. Fakhry SM et al. Management of braininjured patients by an evidence-based medicine protocol improves outcomes and decreases hospital charges. Journal of Trauma, 2004; 56: 492-500.

5. Murdoch B E, Theodoros D G. Introduction: epidemiology, neuro pathophysiology, and medical aspects of traumatic brain injury. Traumatic brain injury: associated speech, language and swallowing disorders. San Diego CA: Singular Thomson Learning; 2001. 1-23.

6. Miller T, Janglois JA, Selassie AW. Prevalence of long-term disability from traumatic brain injury in the civilian population of the United States. J Head Trauma Rehabil, 2008; 23: 394-400.

7. S SDhandapani, D Manju, BS Sharma, A K Mahapatra Prognostic significance of age in TBI, $\mathbf{J}$ Neuroscience in Rural Practice, 2012 May-Aug; 3(2):131-135.

8. Dombovy M L, Olek AC. Recovery and rehabilitation following traumatic brain injury. Brain Injury 1997; 11: 305-318.

9. Wagner AK, Sasser HC, Hammond FM, Wiercisiewski D, Alexander J. Intentional traumatic brain injury: epidemiology, risk factors, and associations with injury severity and mortality. J Trauma, 2000; 49(3): 404-10. Available from www.ncbi.nlm.nih.gov/pubmed

10. Edna TH. Risk factors in traumatic head injury. ActaNeurochir (Wien). 1983; 69(12): 15-21. Available from www.ncbi.nlm.nih.gov/pubmed. 